九州大学学術情報リポジトリ

Kyushu University Institutional Repository

\title{
Introducing Viewpoints of Mechanics into Basic Growth Analysis : (IX) Hypothetic Quasi-Four- Dimensional Growth Mechanics
}

Shimojo, Masataka

Laboratory of Animal Feed Science, Division of Animal Science, Department of Animal and MarineBioresource Sciences, Faculty of Agriculture, Kyushu University

Asano, Yoki

Employed Research Scientist, Miyazaki University

Ishiwaka, Reiko

Research Fellow, Faculty of Agriculture, Kyushu University

Nakano, Yutaka

University Farm, Faculty of Agriculture, Kyushu University

他

https://doi.org/10.5109/14049

出版情報：九州大学大学院農学研究院紀要. 54 (1)，pp.137-139，2009-02-27. Faculty of Agriculture, Kyushu University

バージョン:

権利関係 : 


\title{
Introducing Viewpoints of Mechanics into Basic Growth Analysis - (IX) Hypothetic Quasi-Four-Dimensional Growth Mechanics -
}

\author{
Masataka SHIMOJO*, Yoki ASANO ${ }^{1}$, Reiko ISHIWAKA ${ }^{2}$, Yutaka NAKANO ${ }^{3}$, \\ Manabu TOBISA ${ }^{4}$, Noriko OHBA ${ }^{5}$, Minako EGUCHI ${ }^{6}$ \\ and Yasuhisa MASUDA ${ }^{7}$
}

Laboratory of Animal Feed Science, Division of Animal Science, Department of Animal and Marine Bioresource Sciences, Faculty of Agriculture, Kyushu University, Fukuoka 812-8581, Japan (Received November 14, 2008 and accepted December 5, 2008)

\begin{abstract}
This study was conducted to suggest quasi-four-dimensional basic growth mechanics for the ruminant animal and the forage plant by introducing three-dimensional (3-D) space. Suggested quasi-four-dimensions were composed of width, length from front to back and height of the body frame for 3-D space, and one-dimensional time with which the body frame was formed. The results obtained were as follows. (1) A group of expressions were suggested for weight increase and 3-D body frame formation with the passage of time. (2) A group of expressions were suggested for weight increase with time and 3-D body frame formation with weight increase. (3) A group of expressions were suggested for weight increase based on time and 3-D space, where time and space were treated equally to form weight-space-time relationships. (4) Quasifour-dimensional growth mechanics with feed intake suggested the ruminant animal growth analysis and that with leaf area suggested the forage plant growth analysis. It was suggested that introducing 3-D space with an equal treatment of space and time gave hypothetic quasi-four-dimensional growth mechanics for the ruminant animal and the forage plant.
\end{abstract}

\section{INTRODUCTION}

Basic growth analysis of the ruminant animal (Brody, 1945; Shimojo et al., 1997) and the forage plant (Blackman, 1919; Watson, 1952; Radford, 1967; Hunt, 1990) is given by weight changes with the passage of time. Shimojo et al. (2006, 2007a, 2007b, 2008) introduced viewpoints of mechanics into basic growth analysis to suggest basic growth mechanics with the aid of an analogy with Newton's laws of motion (Kawabe, 2006), which also showed the growth with time. However, the growth is closely related with the formation of body frame not only with time but also in space. This suggests adding the body frame formation in three-dimensional space that is composed of width, length from front to back and height of an individual ruminant animal and forage plant. Combining time and threedimensional space might be expected to give quasifour-dimensional growth mechanics for the ruminant animal and the forage plant.

The present study was designed to investigate the concept of quasi-four-dimensional growth mechanics in analyzing the body frame formation in the ruminant

\footnotetext{
Employed Research Scientist, Miyazaki University, Miyazaki 889-2192, Japan

2 Research Fellow, Faculty of Agriculture, Kyushu University

3 University Farm, Faculty of Agriculture, Kyushu University

${ }^{4}$ Faculty of Agriculture, Miyazaki University, Miyazaki 889-2192, Japan

${ }^{5}$ Former Research Student, School of Agriculture, Kyushu University

${ }_{6}$ Technical Official, School of Agriculture, Kyushu University

7 Emeritus Professor of Kyushu University

* Corresponding author (E-mail: mshimojo@agr.kyushu-u.ac.jp)
}

animal and the forage plant.

\section{SUGGESTED CONCEPT OF QUASI-FOUR \\ DIMENSIONAL GROWTH MECHANICS}

\section{(A) Basic growth mechanics based on time}

The function of basic growth mechanics with the passage of time is given by a series of the following calculations.

$$
\begin{aligned}
& (1 / W) \cdot(d W / d t)=r_{W}, \\
& W=W_{0} \cdot \exp \left(r_{w} \cdot t\right),
\end{aligned}
$$

where $W=$ weight, $t=$ time, $r_{w}=$ relative growth rate (RGR), $W_{0}=$ the weight at $t=0$.

$$
\begin{aligned}
& \mathrm{AGR}=d W / d t=r_{w} \cdot W_{0} \cdot \exp \left(r_{w} \cdot t\right), \\
& \mathrm{GA}=d^{2} W / d t^{2}=r_{w}^{2} \cdot W_{0} \cdot \exp \left(r_{w} \cdot t\right),
\end{aligned}
$$

where AGR=absolute growth rate, GA=growth acceleration.

$$
\begin{aligned}
& \frac{d W / d t}{W}=\frac{d^{2} W / d t^{2}}{d W / d t}=r_{W} \\
& (d W / d t)^{2}=W \cdot\left(d^{2} W / d t^{2}\right) \\
& d W / d t=\sqrt{W \cdot\left(d^{2} W / d t^{2}\right)} .
\end{aligned}
$$

It is differential equation (7) that gives basic growth mechanics of an individual ruminant animal and forage plant (Shimojo et al., 2006). It shows an analogy with Newton's equation of motion (Shimojo et al., 2006, 2007a, 2007b, 2008). 
(B) Basic growth mechanics for body frame formation based on time

The basic growth mechanics for three-dimensional body frame formation of an individual ruminant animal and forage plant is given by the following differential equations when based on the passage of time,

$$
\begin{aligned}
& d x / d t=\sqrt{x \cdot\left(d^{2} x / d t^{2}\right)} \\
& d y / d t=\sqrt{y \cdot\left(d^{2} y / d t^{2}\right)} \\
& d z / d t=\sqrt{z \cdot\left(d^{2} z / d t^{2}\right)}
\end{aligned}
$$

where $x=$ width, $y=$ length from front to back, $z=$ height. Therefore, combining equations (7) and (8) gives a group of differential equations (9) for body frame formation,

$$
\begin{array}{ll}
d W / d t=\sqrt{W \cdot\left(d^{2} W / d t^{2}\right)}, & d x / d t=\sqrt{x \cdot\left(d^{2} x / d t^{2}\right)}, \\
d y / d t=\sqrt{y \cdot\left(d^{2} y / d t^{2}\right)}, & d z / d t=\sqrt{z \cdot\left(d^{2} z / d t^{2}\right)} .
\end{array}
$$

Basic growth functions corresponding differential equations (9) are as follows,

$$
\begin{aligned}
& W=W_{0} \cdot \exp \left(r_{W} \cdot t\right), \quad x=x_{0} \cdot \exp \left(r_{x} \cdot t\right), \\
& y=y_{0} \cdot \exp \left(r_{y} \cdot t\right), \quad z=z_{0} \cdot \exp \left(r_{z} \cdot t\right) .
\end{aligned}
$$

Functions (10) show that weight and space are not related, though each of them is related with time.

\section{(C) Basic growth mechanics for body frame forma-} tion based on weight

The body frame formation is related with the weight, because the distribution of matter forms the body frame. Therefore, the following differential equations are given,

$$
\begin{aligned}
& d W / d t=\sqrt{W \cdot\left(d^{2} W / d t^{2}\right)}, \quad d x / d W=\sqrt{x \cdot\left(d^{2} x / d W^{2}\right)}, \\
& d y / d W=\sqrt{y \cdot\left(d^{2} y / d W^{2}\right)}, \quad d z / d W=\sqrt{z \cdot\left(d^{2} z / d W^{2}\right)}, \\
& W=W_{0} \cdot \exp \left(r_{W} \cdot t\right), \quad x=x_{0} \cdot \exp \left(r_{j} \cdot W\right), \\
& y=y_{0} \cdot \exp \left(r_{k} \cdot W\right), \quad z=z_{0} \cdot \exp \left(r_{i} \cdot W\right) .
\end{aligned}
$$

The relationship between weight $(W)$ and time is different from that between $W$ and space in expressions (11) and (12).

(D) Basic growth mechanics of weight based on time and space

We suggest the following expressions, where $W$ is related with time and space. Thus,

$$
\begin{aligned}
& d W / d t=\sqrt{W \cdot\left(d^{2} W / d t^{2}\right)}, \quad d W / d x=\sqrt{W \cdot\left(d^{2} W / d x^{2}\right)}, \\
& d W / d y=\sqrt{W \cdot\left(d^{2} W / d y^{2}\right)}, \quad d W / d z=\sqrt{W \cdot\left(d^{2} W / d z^{2}\right)}, \\
& W=W_{0} \cdot \exp \left(r_{W} \cdot t\right), \quad W=W_{0} \cdot \exp \left(r_{a} \cdot x\right),
\end{aligned}
$$

$$
W=W_{0} \cdot \exp \left(r_{b} \cdot y\right), \quad W=W_{0} \cdot \exp \left(r_{c} \cdot z\right)
$$

Differential equations (13) suggest that the rate of matter distribution along axes of space and time is described using the product of weight and distribution acceleration. Basic growth functions (14) lead to the following equality (15), and thus equality (16),

$$
\begin{aligned}
& \begin{aligned}
W & =W_{0} \cdot \exp \left(r_{W} \cdot t\right)=W_{0} \cdot \exp \left(r_{\boldsymbol{a}} \cdot x\right)=W_{0} \cdot \exp \left(r_{b} \cdot y\right) \\
& =W_{0} \cdot \exp \left(r_{c} \cdot z\right),
\end{aligned} \\
& r_{W} \cdot t=r_{\boldsymbol{a}} \cdot x=r_{\boldsymbol{b}} \cdot y=r_{c} \cdot z .
\end{aligned}
$$

The feature of equality (16) is that time and space are treated equally and there is an inverse proportion. Thus, if $x<y<z<t$, then $r_{a}>r_{b}>r_{c}>r_{w}$. This shows how much the matter is distributed along not only space axes but also time axis, where $r_{\boldsymbol{a}}, r_{\boldsymbol{b}}, r_{\boldsymbol{c}}$ and $r_{\mathrm{W}}$ suggest values of resistance to matter distribution along each axis of time and three-dimensional space. Equality (15) and equality (16) show weight-space-time relationships, suggesting quasi-four-dimensional growth mechanics.

(E) Basic growth mechanics for the ruminant animal based on time, space and feed intake

The basic growth mechanics of the ruminant animal is given by inserting feed intake $(d F)$ into differential equations (13). The term $d F$ is derived from cumulative feed intake $(F)$ according to the procedure: $F \rightarrow \Delta F \rightarrow d F$. Thus,

$$
\begin{aligned}
& \frac{d W / d t}{d F}=\sqrt{\frac{W}{d F} \cdot \frac{d^{2} W / d t^{2}}{d F},} \\
& \frac{d W / d x}{d F}=\sqrt{\frac{W}{d F} \cdot \frac{d^{2} W / d x^{2}}{d F}}, \\
& \frac{d W / d y}{d F}=\sqrt{\frac{W}{d F} \cdot \frac{d^{2} W / d y^{2}}{d F}}, \\
& \frac{d W / d z}{d F}=\sqrt{\frac{W}{d F} \cdot \frac{d^{2} W / d z^{2}}{d F}} .
\end{aligned}
$$

There are two features in expressions (17). One is that feed intake, as well as weight, is related to space and time, intake-weight-space-time relationships in the growth of the ruminant animal. The other is that feed intake is given to the denominator of every term in expressions, suggesting that the ruminant animal itself and its growth are supported by nutrients of eaten feeds. Expressions (17) suggest, in the ruminant animal body, the matter distribution along axes of space and time based on feed intake.

(F) Basic growth mechanics of the forage plant based on time, space and leaf area

The growth mechanics of the forage plant is given by inserting leaf area $(A)$ into differential equations (13). Thus, 


$$
\begin{aligned}
\frac{d W / d t}{A} & =\sqrt{\frac{W}{A} \cdot \frac{d^{2} W / d t^{2}}{A},} \\
\frac{d W / d x}{A} & =\sqrt{\frac{W}{A} \cdot \frac{d^{2} W / d x^{2}}{A}}, \\
\frac{d W / d y}{A} & =\sqrt{\frac{W}{A} \cdot \frac{d^{2} W / d y^{2}}{A}}, \\
\frac{d W / d z}{A} & =\sqrt{\frac{W}{A} \cdot \frac{d^{2} W / d z^{2}}{A}} .
\end{aligned}
$$

There are two features in expressions (18). One is that leaf area, as well as weight, is related to space and time, leaf-weight-space-time relationships in the growth of the forage plant. The other is that leaf area is given to the denominator of every term in expressions, suggesting that the forage plant itself and its growth are supported by photosynthesis of leaves. Expressions (18) suggest, in the forage plant body, the matter distribution along axes of space and time based on leaf area.

\section{(G) Problems}

The concept suggested to quasi-four-dimensional growth mechanics is only a hypothesis that includes many problems. Expressions suggested here include terms whose forms may look strange. Treating time and space equally may look illogical. Weight-space-time relationships may look unnatural. There is a need of further studies that will correct problems and introduce new ideas in order to develop growth mechanics with four-dimensions for the ruminant animal and the forage plant.

\section{(H) Conclusions}

It is suggested from the present study that introducing three-dimensional space with an equal treatment of space and time gives hypothetic quasi-four-dimen- sional growth mechanics for the ruminant animal and the forage plant.

\section{REFERENCES}

Blackman, V. H. 1919 The compound interest law and plant growth. Ann. Bot., 33: 353-360

Brody, S. 1945 Time relations of growth of individuals and populations. In "Bioenergetics and Growth - with special reference to the efficiency complex in domestic animals", Reinhold Publishing Corporation, New York, pp. 484-574

Hunt, R. 1990 Basic Growth Analysis. Unwin Hyman Ltd., London.

Kawabe, T. 2006 Standard Mechanics. Shokabo Publishing Co., Ltd., Tokyo. (written in Japanese)

Radford, P. J. 1967 Growth analysis formulae-their use and abuse. Crop Sci., 7: 171-175

Shimojo, M., T. Bungo, Y. Imura, M. Tobisa, N. Koga, Y. Nakano, I. Goto and Y. Masuda 1997 Relative growth rate of beef cattle expressed using factors related to feed intake, maintenance requirements and feed efficiency. J. Fac. Agr., Kyushu Univ., 42: 87-93

Shimojo, M., K. Ikeda, Y. Asano, R. Ishiwaka, H. Sato, Y. Nakano, M. Tobisa, N. Ohba, M. Eguchi and Y. Masuda 2006 Introducing viewpoints of mechanics into basic growth analysis - (I) Three aspects of growth mechanics compared with three laws of motion -. J. Fac. Agr., Kyushu Univ., 51: 285-287

Shimojo, M., K. Ikeda, Y. Asano, R. Ishiwaka, H. Sato, Y. Nakano, M. Tobisa, N. Ohba, M. Eguchi and Y. Masuda 2007a Introducing viewpoints of mechanics into basic growth analysis - (III) Applying growth force and leaf-light complex to production and digestion analyses of forages -. J. Fac. Agr., Kyushu Univ., 52: 69-72

Shimojo, M., Y. Asano, R. Ishiwaka, H. Sato, Y. Nakano, M. Tobisa, N. Ohba, M. Eguchi and Y. Masuda 2007b Introducing viewpoints of mechanics into basic growth analysis - (VI) Some solutions to a simple differential equation associated with growth mechanics -. J. Fac. Agr., Kyushu Univ., 52: 361-365

Shimojo, M., T. Shao and Y. Masuda 2008 Introducing viewpoints of mechanics into basic growth analysis - (VII) Mathematical properties of basic growth mechanics in ruminant -. J. Fac. Agr., Kyushu Univ., 53: 453-458

Watson, D. J. 1952 The physiological basis of variation in yield. Adv. Agron., 4: 101-145 